\title{
The relation of glycaemia to the risk of development and progression of retinopathy in the Diabetic Control and Complications Trial
}

\author{
F. J.Service' ${ }^{1}$, P.C. O'Brian ${ }^{2}$ \\ ${ }^{1}$ Division of Endocrinology, Metabolism and Nutrition, Mayo Clinic and Foundation, Rochester, Minnesota, USA \\ ${ }^{2}$ Department of Biostatistics, Mayo Clinic and Foundation, Rochester, Minnesota, USA
}

Diabetologia (2001) 44: 1215-1220

There was a typing error on page 1216, in the Glycaemic parameters paragraph of the Subjects and methods section: ' $10 \log \mathrm{BG} / 90$ ' in the M-value formula should read: ' $10 \log \mathrm{BG} / 90$ '

\section{A choice of death - the signal-transduction of immune-mediated beta-cell apoptosis}

\section{L. Eizirik ${ }^{1}$, T.Mandrup-Poulsen ${ }^{2}$}

${ }^{1}$ Gene Expression Unit, Diabetes Research Center, Vrije Universiteit Brussel, Brussels, Belgium

${ }^{2}$ Steno Diabetes Center, Gentofte, Denmark

Diabetologia (2001) 44: 2115-2133

Table 4 should read as follows:

Table 4. Systemic cytokine-deficient NOD mice models

\begin{tabular}{ll}
\hline Deficiency & Protection vs diabetes \\
\hline IFNg [82] & - \\
IFNg receptor a-chain [83] & + \\
IFNg receptor b-chain [84] & - \\
IL-12 [85] & - \\
IL-4 [87] & - \\
IL-4 receptor [86] & + \\
\hline
\end{tabular}

Additional correction:

Page 2115 in the Abbreviations: IKK, inhibitory kB kinase. 